\title{
A novel hybrid catheter-directed technique to treat intermediate-high risk pulmonary embolism
}

\author{
Sylwia L. Sławek-Szmyt@, Stanisław Jankiewicz, Marek Grygier, \\ Maciej Lesiak, Aleksander Araszkiewicz® \\ $1^{\text {st }}$ Department of Cardiology, Poznan University of Medical Sciences, Poznan, Poland
}

\begin{abstract}
Despite advances in the management of acute pulmonary embolism (PE), the mortality rate in intermediate-high-risk and high-risk PE remains significant $[1,2]$. Recently, percutaneous catheterdirected therapies have progressed with contemporary PE management [3-6].

A 44-year-old woman with a history of disseminated ovarian cancer was admitted with intermediate-high risk PE. Several days of unfractionated heparin (UFH) infusion was ineffective despite therapeutic range of activated partial thromboplastin time (APTT). Physical examination revealed heart rate (HR) $120 \mathrm{bpm}$, respiratory rate (RR) 30/ $/ \mathrm{min}$ and blood pressure (BP) 95/60 mmHg. Blood test showed elevated troponin concentration $0.6 \mathrm{ng} / \mathrm{L}$ (normal range $<0.01 \mathrm{ng} / \mathrm{L}$ ) and low arterial saturation $\left(\mathrm{SaO}_{2}\right)$ 88\% despite oxygen supplementation (flow rate $15 \mathrm{~L} / \mathrm{min}$ ). Echocardiography demonstrated right ventricle dysfunction (right ventricle/ /left ventricle [RV/LV] diameter ratio 1.5 and tricuspid annular plane systolic excursion [TAPSE] $13 \mathrm{~mm}$ ). A bedside lower-limb compression ultrasonography showed a deep vein thrombosis of the left popliteal vein. The Pulmonary Embolism Severity Index indicated very high mortality risk (144 points - class V). Our institutional PE response team qualified the patient to catheter-directed treatment.

The right common femoral venous access was obtained with a $6-\mathrm{F}$ vascular sheath. A pigtail catheter (6-F; Cordis, Hileah) was inserted into the right and left pulmonary arteries and a selective angiography was performed. Then, pulmonary arterial pressures (PAPs) were recorded under fluoroscopy according to current guidelines [7]. The systolic/diastolic/mean PAPs were 63/17/35
\end{abstract}

$\mathrm{mmHg}$, respectively. Pulmonary angiography revealed large thrombus burden bilaterally mainly in lobar pulmonary arteries.

Due to well thrombi organization it was decided to give alteplase directly to the thrombus in preparation for aspiration.

For this purpose, an angioplasty balloon catheter Maverick $2^{\text {TM }} 4.0 \times 20 \mathrm{~mm}$ (Boston Scientific, Marlborough) was manually perforated with a needle at different sites and subsequently inserted into the target segmental artery of the right upper lobe tracked along Sion blue guidewire (Ashahi, Aichi). The balloon catheter was inflated with an alteplase solution (concentration $1 \mathrm{mg} / 1 \mathrm{~mL}$ ) using a deployment pressure of 6 atmospheres (Fig. $1 \mathrm{~A}-\mathrm{F})$. The balloon catheter was subsequently placed and inflated in the two other segmental arteries of the right upper lobe. The total amount of $3 \mathrm{mg}$ of alteplase was injected via the balloon catheter within $3 \mathrm{~min}$ - each inflation lasted $1 \mathrm{~min}$.

Subsequently, a $115 \mathrm{~cm}, 8-\mathrm{F}$ Indigo CAT8 XTORQ catheter (Penumbra, Alameda, California) was inserted through a long $90 \mathrm{~cm}, 8 \mathrm{~F}$ Flexor sheath (Cook; Bloomington) to perform continuous aspiration thrombectomy (CDT) procedure in the right and left lobar pulmonary arteries. A directaspiration first-pass technique was performed in order to attach a large part of the thrombus to the catheter tip by suction and then pull it out through the sheath. Subsequently, separator wire was repeatedly passed through the thrombus to fragment and facilitate aspiration (Fig. 1G-I). The procedure was terminated with the improvement of hemodynamic parameters (on table HR normalization $<100 \mathrm{bpm}$ and PAPs reduction to $46 / 15 / 26 \mathrm{mmHg}$ ).

Address for correspondence: Sylwia L. Sławek-Szmyt, MD, PhD, $1^{\text {st }}$ Department of Cardiology, Poznan University of Medical Sciences, ul. Długa 1/2, 61-848 Poznań, Poland, tel/fax: +48 6185491 46, e-mail: sylwia.slawek@skpp.edu.pl

Received: 24.08.2021 Accepted: 5.02.2022 Early publication date: 18.02.2022

This article is available in open access under Creative Common Attribution-Non-Commercial-No Derivatives 4.0 International (CC BY-NC-ND 4.0) license, allowing to download articles and share them with others as long as they credit the authors and the publisher, but without permission to change them in any way or use them commercially. 


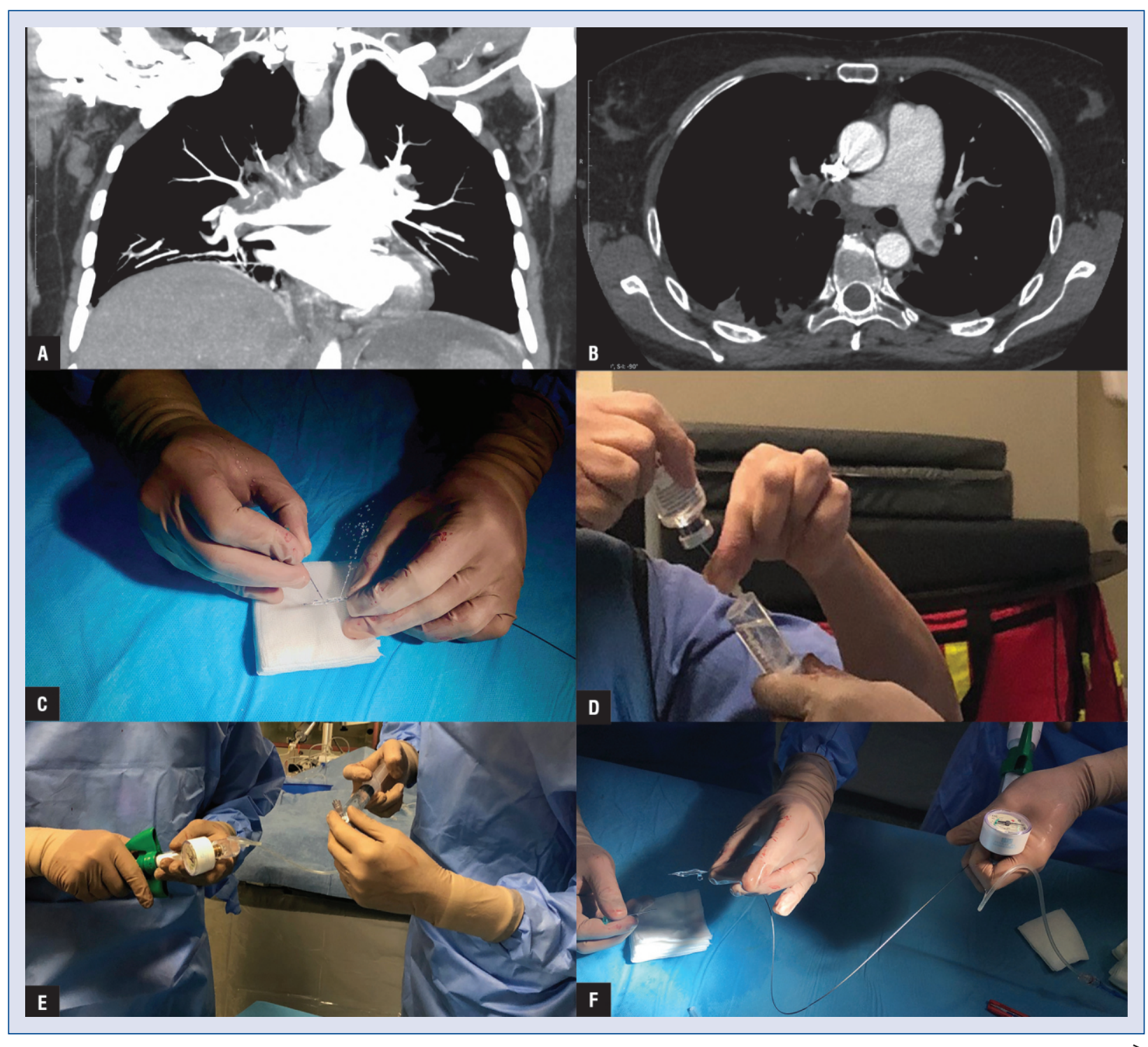

Eventually, blood flow significantly improved bilaterally in proximal pulmonary arteries as well in the lung periphery. During the procedure, intravenous UFH was continued at normal intensity with a goal APTT of 1.5-2.5 upper normal range.

During the subsequent monitoring in the cardiac intensive unit the patient's clinical status significantly improved. There were no complications related to the procedure. 24 hours after CDT patient's $\mathrm{HR}$ was $80 \mathrm{bpm}$, RR was $20 / \mathrm{min}$ and $\mathrm{SaO}_{2}$ was $94 \%$ on room air, respectively. Echocardiography showed significant RV function improvement (TAPSE $20 \mathrm{~mm}, \mathrm{RV} / \mathrm{LV}$ diameter ratio 1.0). Anticoagulation with UFH was continued for 48 hours after the procedure and then a weight-adjusted low molecular weight heparin was introduced. The clinical 6-month follow up was uneventful and the patient continued with chemotherapy.
Interventional techniques are focused to quickly relieve blockage and restore pulmonary blood flow with subsequent improvement in hemodynamic status, oxygenation and RV function $[8,9]$. The use of two catheter-directed techniques, balloon-delivered local thrombolysis and continuous aspiration thrombectomy, during one procedure was unique. In the present case, efficient clot removal immediately improved the patient's condition and appeared important to ameliorate the outcome with low bleeding risk. An alteplase given directly into the pulmonary arterial circulation reaches a steady-state and is capable of dissolving thrombi [10]. It was decided to administer a thrombolytic drug directly into the segmental arteries to provide the highest drug concentration in most obstructed vessels. These results suggest a possible synergistic effect of low dose 


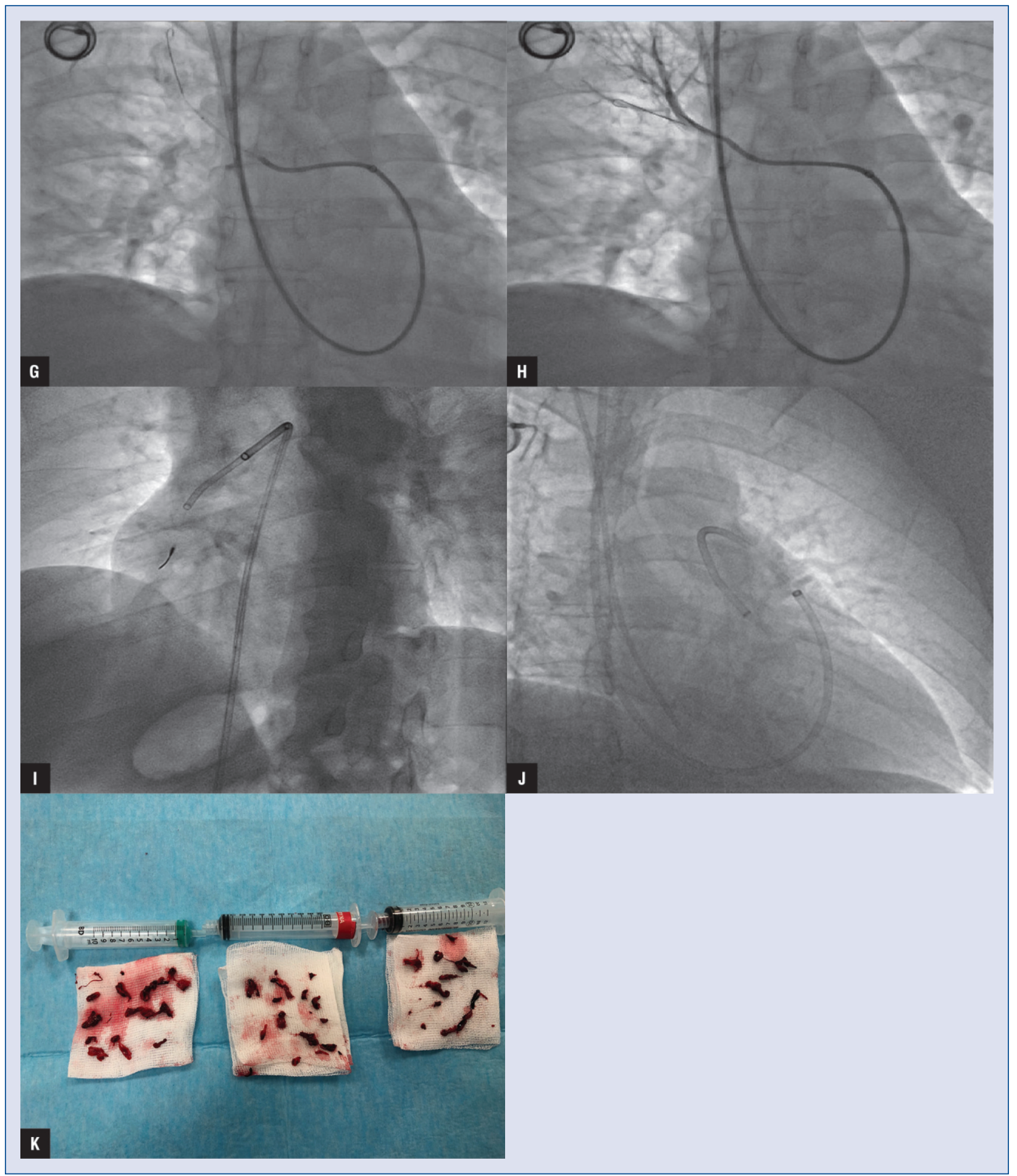

Figure 1. Step by step a hybrid catheter-directed treatment of pulmonary embolism; A, B. The initial computed tomography angiograms showing extensive thromboembolic material burden in right pulmonary arteries; C. The angioplasty balloon perforation with a needle at different sites; $\mathbf{D}$. The alteplase solution preparation (concentration $1 \mathrm{mg} / 1 \mathrm{~mL}$ ); E, F. Filling of the handheld pump and the angioplasty balloon with the alteplase solution; $\mathbf{G}$. The angioplasty balloon placement and inflation with the alteplase solution into the target segmental artery of the right upper lobe; $\mathbf{H}$. The selective angiogram performed after transballoon alteplase delivery; I, J. The catheter-directed mechanical aspiration thrombectomy procedure with the Indigo device; K. An image of the removed clots. 
thrombolytic therapy and aspiration thrombectomy, even in patients with a relatively long duration of PE symptoms.

\section{Conflict of interest: None declared}

\section{References}

1. Konstantinides SV, Meyer G, Becattini C, et al. The Task Force for the diagnosis and management of acute pulmonary embolism of the European Society of Cardiology (ESC). 2019 ESC Guidelines for the diagnosis and management of acute pulmonary embolism developed in collaboration with the European Respiratory Society (ERS): The Task Force for the diagnosis and management of acute pulmonary embolism of the European Society of Cardiology (ESC). Eur Respir J. 2019; 54(3), doi: 10.1183/13993003.01647-2019, indexed in Pubmed: 31473594 .

2. Sławek-Szmyt S, Jankiewicz S, Smukowska-Gorynia A, et al. Implementation of a regional multidisciplinary pulmonary embolism response team: PERT-POZ initial 1-year experience. Kardiol Pol. 2020; 78(4): 300-310, doi: 10.33963/KP.15230, indexed in Pubmed: 32165606.

3. Sista AK, Horowitz JM, Tapson VF, et al. Indigo aspiration system for treatment of pulmonary embolism: results of the extract-pe trial. JACC Cardiovasc Interv. 2021; 14(3): 319-329, doi: 10.1016/j.jcin.2020.09.053, indexed in Pubmed: 33454291.

4. Araszkiewicz A, Sławek-Szmyt S, Jankiewicz S, et al. Continuous aspiration thrombectomy in high- and intermediate-high-risk pulmonary embolism in real-world clinical practice. J Interv Cardiol. 2020; 2020: 4191079, doi: 10.1155/2020/4191079, indexed in Pubmed: 32904502.
5. Araszkiewicz A, Kurzyna M, Kopeć G, et al. Expert opinion on the creating and operating of the regional Pulmonary Embolism Response Teams (PERT). Polish PERT Initiative. Cardiol J. 2019; 26(6): 623-632, doi: 10.5603/CJ.2019.0127, indexed in Pubmed: 31970735.

6. Stępniewski J, Kopeć G, Musiałek P, et al. Hemodynamic effects of ultrasound-assisted, catheter-directed, very low-dose, short-time duration thrombolysis in acute intermediate-high risk pulmonary embolism (from the EKOS-PL study). Am J Cardiol. 2021; 141: 133-139, doi: 10.1016/j.amjcard.2020.11.004, indexed in Pubmed: 33220318.

7. Kurzyna M, Araszkiewicz A, Błaszczak P, et al. Summary of recommendations for the haemodynamic and angiographic assessment of the pulmonary circulation. Joint statement of the Polish Cardiac Society's Working Group on Pulmonary Circulation and Association of Cardiovascular Interventions. Kardiol Pol. 2015; 73(1): 63-68, doi: 10.5603/KP.2015.0011, indexed in Pubmed: 25625343.

8. Araszkiewicz A, Kurzyna M, Kopeć G, et al. Pulmonary embolism response team: A multidisciplinary approach to pulmonary embolism treatment. Polish PERT Initiative Report. Kardiol Pol. 2021; 79(12): 1311-1319, doi: 10.33963/KP.a2021.0130, indexed in Pubmed: 34643260.

9. Ruzsa Z, Vámosi Z, Berta B, et al. Catheter directed thrombolytic therapy and aspiration thrombectomy in intermediate pulmonary embolism with long term results. Cardiol J. 2020; 27(4): 368-375, doi: 10.5603/CJ.a2020.0060, indexed in Pubmed: 32329040.

10. Güner A, Kalçik M, Aykan AÇ, et al. Clinical safety and efficacy of thrombolytic therapy with low-dose prolonged infusion of tissue type plasminogen activator in patients with intermediate-high risk pulmonary embolism. Blood Coagul Fibrinolysis. 2020; 31(8): 536-542, doi: 10.1097/MBC.0000000000000960, indexed in Pubmed: 33181758. 